\title{
A MULHER NO ENSINO SUPERIOR EM ODONTOLOGIA NO BRASIL
}

* Académica da Faculdade de Odontologia da UFRGS

* *Cirurgião Dentista, Mestre em Saúde Pública e Professor da Faculdade de Odontologia da UFRGS 


\section{REFERÊNCIA BIBLIOGRÁFICA}

SILVEIRA, Heloisa \& CORDON. J. A mulher no ensino superior em odontologia no Brasil. Revista da Faculdade de Odontologia. Porto Alegre, 26: 25-36, 1984.

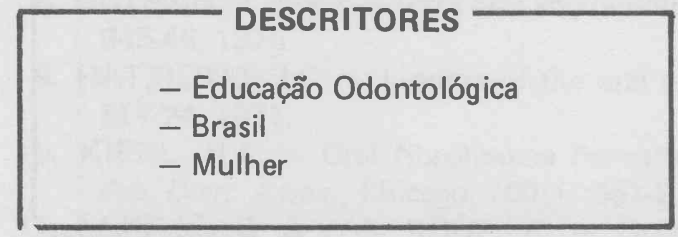

\section{RESUMO}

Se colocam as respostas que professoras de Faculdades de Odontologia deram a um questionário enviado, sobre sua situação, analisando-se brevemente a informação obtida e sugerindo aprofundar no estudo do problema.

Uma população jovem de professoras, solteiras, assistentes, que se dedicam a Odontopediatria e Odontologia Social e que não tiveram problemas para o seu ingresso nas Faculdades, constitui o perfil encontrado na pesquisa. 


\section{A MULHER NO ENSINO SUPERIOR EM ODONTOLOGIA NO BRASIL}

\section{INTRODUÇÃO}

Pouca informação tem-se obtido sobre o papel da mulher no Ensino Superior em Odontologia, especialmente na conjuntura econômica dos últimọs anos em que a identificação homemliulher, desde o ponto de vista social, tende a equiparar-se, sem perder o elemento caracter ístico feminino.

Parece estar superada a divisão econômica social entre homem e mulher a nível geral, ainda que contrasta com a situação que consegue obter no Ensino Superior e especialmente em Odontologia.

Este contraste pode identificar-se numa primeira aproximação ao estudo do papel da mulher em Odontologia, particularmente com docente nos diferentes Cursos, Departamentos e Faculdades de Odontologia do Brasil.

Neste trabalho se descreve uma pesquisa com professoras de Odontologia, no Brasil, a fim de consultar sobre sua participação no contexto global do ensino superior.

\section{REVISÃO DA LITERATURA}

Pouca informação se tem da situação feminina no Ensino Superior de Odontologia. Ao revisar a literatura os dados encontrados são mínimos, referindo-se a informação geral sobre número de professoras por Faculdade, grau acadêmico e disciplinas que lecionam (3).

O Conselho Federal de Odontologia publicou informação sobre 1980 (3), indicando que em 60 Faculdades, Escolas ou Departamentos de Odontologia no Brasil existiam 4132 professores, dos quais $755(18,3 \%)$ eram do sexo feminino.

Ao mesmo tempo se observa que 1257 dos professores tinham título de Mestrado, Doutorado e Livre Docência. Ao sexo feminino cabe 137 mestres $(28,4 \%)$ dos 483 constantes; $39(8,2 \%)$ Doutoras e 29 professoras $(9,7 \%)$ dos 300 livres docentes existentes na Universidade. (3)

Estes dados já falam da pouca participação das mulheres no ensino de Odontologia, observando-se algum tipo de marginalização no sentido de igualdade de oportunidade e aquisição de cargos docentes na Universidade Brasileira.

Com respeito à participação feminina no corpo docente no Brasil, o que se observa e que quanto mais elevado o nivel de ensino, menor a participação feminina no corpo docente.

Enquanto no ensino de 1? grau elas perfazem a maioria $(86,8 \%)$, já no ensino superior isto não ocorre, caindo a percentagem de participação a níveis muito baixos (16\%).

Há estudos que mostram que a regularidade da participação feminina é inversamente proporcional ao prestígio do posto. (13)

Como mencionado por Rosemberg et ali; (13), quando o sexo masculino deixa de trabalhar em determinada área, educação, por exemplo, para lá confluem um grande número de mulheres.

Como o mercado de trabalho para o homem com diploma universitário é mais diversificado, as mulheres passaram a procurar cada vez mais os lugares antes ocupados por ele no ensino médio. Isto ligado à crescente perda do prestígio desta profissão em virtude da "popularização" das escolas de 1? e 
2 . graus numa cultura que valoriza 0 elitismo e o previlégio.

"O circuito escolar, canalizando grande parte do contingente feminino egresso da Universidade, concorre para diminuir a sua competitividade com os homens em outras esferas ocupacionais". (13)

"O impacto que causaram as constatações de HORNER (1968) sobre o medo do sucesso, presente e comum entre mulheres inteligentes, indica o quanto ainda somos ignorantes sobre os me canismos psicológicos profundos, conseqüentes a sua socialização divididas entre a maternidade e o trabalho profissional, e que constituem freios formidáveis à vontade de inovação. $A$ absorção, melhor seria mesmo dizer a impregnação, deste modelo tradicional e ambíguo se efetua para além dos muros domésticos, estando presente na rua, na igreja, nos meios de comunicação, na escola". (13)

A mulher é um dos alvos prediletos da comunicação das massas, (7) que tenta, mediante uma nova ordem de representação simbólica, conseguir que a muIher cumpra as duas funções gerais que o sistema lhe assegura 1) a missão de pacificar, equilibrar e resolver certas contradições especiais dos sistemas (na família, educação), e 2) assumir e interiorizar o papel de "pilar da economia de apoio" (reconstituição da força de trabalho mediante o trabalho invisível, desvalorizado, não pagol que assegura o funcionamento do sistema e permite uma alta extração de mais valia do trabalho do marido e, indiretamente, também do trabalho da mulher. Ou seja um papel regulador na economia capitalista (trabalho doméstico não pago, exército laboral de reserva barato, disciplinado e consumista) e papel reprodutor da ideologia dominante (interiorização e transmissão de imagens e símbolos, educa- ção, garantia do equilíbrio moral e afetivo, etc). (13)

No censo de 1980 (6) se observa que a participação da mão de obra feminima no mercado de trabalho subiu de $18,51 \%$ em 1970 para 27,47\% em 1980 . Este aumento é considerável, quando se analisa o ppapel da mulher na força de trabalho do país, sobre tudo quando se sabe que acumula a sua jornada diária, o trabalho doméstico, não remunerado, somando em média um total de 13 horas de trabalho.

O anterior permite observar que existe uma diferenciação entre o sexo masculino e o feminino na divisão do trabalho, com repercussões no econômico, político, ideológico e em geral no social, marginando à mulher no processo de vida de toda uma sociedade. Diversos autores $(4,14,15)$ tem estudado estes aspectos e concluido com a situação de desvantagem da mulher no modo de vida de um país da área capitalista.

Especificamente em saúde, a estrutura ocupacional da força de trabalho nos Estados Unidos da América, é predominantemente feminina, pobremente paga e pobremente unida. (11)

Existe ausência virtual da mulher no processo decisório das instituições de saúde. (11) Esta discriminação não é particular, neste setor, é em toda a sociedade, assim, quando se fala de libertação da mulher, implica necessariamente na libertação de cada um, de todos.

Ainda assim, a Organização Mundial da Saúde (12) anunciava em 1981 o aumento da proporção de mulheres no sętor Saúde em ao redor de $18 \%$.

A mesma fonte coloca exemplos da União Soviética e Estados Unidos com algumas diferenças. Na União Soviética existiam na data 670.000 médicos e Dentistas, 480.000 eram mulheres; nos Estados Unidos existiam 370.000 e 29.000 unicamente eram mulheres, le- 
ventando com isto a hipótese de que são as decisões polfticas de um país - ou a vontade política - acima de tudo, que influenciam a proporção de mulheres nas profissões da saúde.

Se tem estudado a situação da saúde da mulher e o desenvolvimento, especialmente no terceiro mundo, (16) colocando a marginalização que sofre em todos os aspectos que se relacionam com o seu desenvolvimento biofísico e psico-sócio cultural.

Também se tem chamado à atenção (10) para a necessidade da mulher ocupar espaços decisórios em todos os nlveis, especialmente nos sistemas de saúde, reconhecendo que onde pior representadas estão as mulheres é nas categorias superiores.

Se enfatiza, (5) por outra parte, o valioso papel exercido pela mulher em algumas profissões específicas, como na enfermagem, ainda que tem tido obstáculos legais para confiar as funçס̋es mais importantes à profissão.

As necessidades e interesses das muIheres raramente são tomados em consideração na planificação das políticas de saúde e educação.

Quando se discute especificamente a mulher em Odontologia, e mais particularmente em educação superior, poucas referências são encontradas, e em geral, os estudos são feitos muito abrangentes e sem aprofundar no problema. (9)

Nos Estados Unidos tem-se realizado alguns estudos que revelam parte da situação da mulher.

Em 1973 as mulheres constituiam 1,5\% dos dentistas nos Estados Unidos. (1) As razões mencionadas para essa situação se relacionaram com a contradição da demanida de cuidado dental e a demanda pelo papel de esposa e mãe, assim como as formas de discriminação que a mulher sofria no processo de seleção, formação e trabalho profissional.
Num estudo realizado na Escola Dental de New Jersey, encontrou-se que $77 \%$ das mulheres não observaram discriminação no seu desenvolvimento profissional, sendo que as dificuldades encontradas eram similares para homens e mulheres. (1)

Em relação à atitude dos colegas respeito às mulheres no desenvolvimento de suas atividades, a mesma pesquisa mostrou que $15,4 \%$ mostravam atitude negativa à mulher, $23,1 \%$ atitude positiva e igual tratamento para ambos os sexos $61,5 \%$, (1)

Mc Greary e Gershen (8) estudaram as mudanças na personalidade entre graduados de Odontologia do sexo masculino e feminino.

O estudo examina as mudanças na personalidade durante sua vida de estudantes e após graduados. Analisa que os dentistas especialmente as mulheres, são menos competitivas, enérgicas e manipuladora de situações no consultório.

Em geral, observaram que diminui a iniciativa e independência e aumenta a conformidade, aceitação e convencibilidade. As mulheres diminuem em empatia e viram mais egocêntricas conforme o tempo passa no trabalho. (8)

Em outro estudo (1) encontraram maiores percentagens de solteiras que solteiros, assim como com respeito as disciplinas de maior procura, se notou que cirurgia é mais masculina e em Ortodontia, Saúde Pública, Endodontia, Prótese e Periódontia não se encontraram diferenças por sexo nas pessoas que o praticaram em graduação.

Com respeito à higienistas, Mendes e Mendes (9) manifestam ter uma vida profissional curta, porque o casamento geralmente induz ao abandono da profissão. Tal fato faz com que se tente eliminar as restrições legais e educacionais aos higienistas do sexo masculino. 
Bustos (2) realizou um estudo sobre o tempo útil exercício profissional Odontológico, segundo sexo, no Brasil.

No estudo, se conclui que as mulheres trabalham ao redor de $30 \%$ menos tempu no consultório que o sexo masculino, isto por semana e anualmente.

Enquanto o sexo feminino trabalha no consultório privado só $40 \%$, o homem o faz $60 \%$ sendo que as mulheres dentistas desenvolvem mais um trabalho que utiliza o consultório privado e outras formas infstitucionais que os homens.

A diminuição do tempo de trabalho da mulher, segundo Bustos, (2) se deve ao casamento, gravidez, afazeres domésticos, falta de estímulo.

\section{MATERIAL E TÉCNICAS}

Para analisar algumas das características da mulher na Odontologia, se definiu como universo a ser estudado, as professoras das Faculdades de Odontologia que, em 1980, trabalhavam nestas instituições, fazendo um levantamento sobre as principais áreas de trabalho.

Segundo o Conselho Federal de Odontologia (3), 755 professoras atuavam nos 67 cursos, departamentos ou Faculdade de Odontologia no Brasil.

Após eliminar os nomes, que se repetiam por trabalhar em mais de uma Faculdade e aqueles que indicavam pertencer a outras profissões da saúde, como também as Faculdades ou instituições que não tinham especificado o sexo dos professores, se conclui que existiam 682 professoras que constituiram o universo de trabalho, em 60 Faculdades de Odontologia.

A todas elas foi enviado, por correio, um questionário para solicitar informação sobre os aspectos mais importantes da situação da mulher no trabaIho como docente em Odontologia. A informação foi organizada e tabulada a fim de poder levantar uma discussão original.

\section{RESULTADOS}

Dos 682 questionários enviados, fo: ram recebidos 69 respostas, o que representa $10 \%$ do universo de estudo.

As 69 respostas procediam de 32 Faculdades ou Escolas de Odontologia, ou seja $50 \%$ das instituições constantes na amostra.

A idade média das pessoas que responderam é de 37 anos variando de 25 até 63 anos de idade. (Quadro n? 1).

Com respeito ao estado civil 37 (54\%) eram casadas, 27 eram solteiras e unicamente 2 viúvas, 1 separada, 1 divorciada e 1 desquitada.

Quanto ao número de filhos verificou-se que 37 (54\%) não tinham filhos, 15 tinham 2 filhos, 7 tinham 1 filho, 6 tinham 3 filhos e 3 tinham 4 filhos.

A maior porcentagem de docentes do sexo feminino é assistente, encontrando-se uma porcentagem mínima de titulares. (Ver quadro n? 2).

Q Ano de Graduação tem, na amostra de respostas recebidas, uma maior quantidade de professores jovens, onde quase $50 \%$ obteve o Grau nos últimos 10 anos.

Perguntadas sobre se tinham enfrentado problemas para tornar-se professoras de Faculdade, $85 \%$ das que responderam ao questionário, colocaram que não e $13,2 \%$ responderam que sim.

As disciplinas de Odontopediatria e Odontologia Social resultam ser as áreas mais procuradas pelas docentes (quadro n? 3), seguidas das áreas Básicas, Ortodontia e Dentística.

O motivo da escolha da profissão de Cirurgião Dentista resultou ser $68 \%$ a opção técnico científica, $26 \%$ tinham 


\section{QUADRO N: 1}

Idade das professoras de Odontologia do Brasil que responderam o questionário em 1982.

\begin{tabular}{|l|c|}
\hline IDADE & No DE RESPOSTAS \\
\hline $25-29$ & 09 \\
$30-34$ & 22 \\
$35-39$ & 17 \\
$40-44$ & 12 \\
$45-49$ & 04 \\
$50-54$ & 03 \\
$55-$ & 01 \\
N5๊o respt. & 01 \\
\hline TOTAL & 69 \\
\hline
\end{tabular}

FONTE: Pesquisa.

\section{QUADRO N? 2}

Posição que ocupam as professoras de Odontologia no Brasil. 1982.

\begin{tabular}{|l|c|c|}
\hline CATEGORIA & NO DE RESPOSTAS & $\%$ \\
\hline Assistente & 39 & 57 \\
Adjunto & 17 & 25 \\
Livre Docente & 05 & 7 \\
Auxiliar & 05 & 7 \\
Titular & 02 & 3 \\
Substituta & 01 & 1 \\
\hline TODAS & 69 & 100 \\
\hline
\end{tabular}

FONTE: Pesquisa realizada. 


\section{QUADRO N? 3}

Disciplinas em que trabalham as professoras nas Faculdades de Odontologia no Brasil. 1982.

\begin{tabular}{|l|c|}
\hline DISCIPLINAS & NO DE RESPOSTAS \\
\hline Odontopediatria & 14 \\
Odontologia Social & 13 \\
Ciências Básicas & 08 \\
Ortodontia & 07 \\
Dentística & 07 \\
Patologia Oral & 06 \\
Radiologia, Diagnóstico Oral e Semiologia & 06 \\
Cirurgia & 03 \\
Clínica Integrada & 02 \\
Serviço de Urgência & 01 \\
Estomatologia & 01 \\
Prótese Dentária & 01 \\
\hline TODAS & 69 \\
\hline
\end{tabular}

FONTE: Pesquisa

vários motivos, 4 responderam opção familiar e 2 opção econômica.

Quanto a pós-graduação, 39 das 69 que responderam, apresentavam curso de mestrado, 21 eram especialistas e 6 haviam feito doutorado. Observou-se que $85 \%$ delas trabalhava na mesma área em que fizeram cursos, e $15 \%$ trabalhava em outras áreas.

Sobre o que motivou a escolha de pós-graduação, responderam que queriam adquirir maior conhecimento e melhorar as condições de ensino da disciplina escolhida e que sentiam interesse pelo ensino.

Das 69 respostas obtidas, $84 \%$ não haviam enfrentado problemas no seu ingresso ao trabalho pelo fato de serem do sexo feminino e $15 \%$ tinham encontrado problemas.
A média de professores do sexo feminino nas faculdades em que trabaIham é de $30 \%$.

A maioria delas năo exerce outra função além do magistério.

Das professoras, 53 responderam que não foi difícil começar a exercer a profissão recém formadas, 12 responderam que tiveram problemas e 2 não responderam, assim também, 36,8\% responderam não ter tido problemas para conciliar a vida familíar com a profissional $17,6 \%$ tiveram problemas e $36,8 \%$ não responderam.

Quanto ao fato de ter recebido ou não os direitos legais quando tiveram seus filhos, 26 das 69 professoras receberam tempo completo de gravidez (90 dias), 17 receberam salário gravidez, 14 receberam permissão para gestantes, 
4 responderam que não recéberam nada, 3 receberam outros auxílios e uma recebeu só numa gravidez.

Com respeito ao abandono da profissão, ou afastamento temporário, 51 das professoras nunca pensaram em abandonar a profissão, 6 já abandonaram e voltaram as atividades e 4 já pensaram em abandonar.

Como mulher, 59 responderam que não tiveram problemas no desenvolvimento do curso de graduação, 5 tiveram problemas 4 não responderam esta pergunta.

Sobre a diferença de posição que a mulher ocupa hoje na Odontologia, 69\% responderam ter notado diferenças, comparando com a época em que se graduaram, $28 \%$ responderam não ter notado diferenças. Assim também parece ser que o tratamento recebido nas instituições que laboram é igual aos colegas masculinos, segundo pode observar-se no Quadro n? 4.

\section{QUADRO N: 4}

Relação das professoras com respeito ao tratamento dos colegas.

Brasil. 1982.

\begin{tabular}{|l|c|}
\hline SITUAÇÃO & NO DE RESPOSTAS \\
\hline Igual aos colegas & 40 \\
É diferente & 08 \\
Diferente negativamente aos colegas & 06 \\
Muito melhor tratada que os colegas & 05 \\
Diferente positivamente aos colegas & 05 \\
Outros & 05 \\
\hline TOTAL & 69 \\
\hline
\end{tabular}

FONTE: Pesquisa

Das 69 professoras de odontologia que responderam ao questionário, 41 gostariam de participar de uma organização científica pelo melhoramento da mulher profissional, 23 não gostariam e 4 não responderam esta pergunta.

Das respostas à pergunta sobre os problemas apresentados nas instituições empregadoras, por ser do sexo feminino, se colocam a continuação as mais relevantes:

"Pretendia ser professora de Dentística, inclusive trabalhava no consultó- rio com o Chefe de Departamento, e ele me indicou para a Odontopediatria, pois no Departamento não tinha nenhuma mulher (não queriam mulheres no Departamento)".

"Ser por alguns considerada como objeto".

"Na faculdade houve uma espécie de mágoa, despeito, desrespeito por parte de $80 \%$ dos colegas do sexo masculino".

"O Chefe do Departamento da área de clínica, não aceitava mulheres traba- 
Ihando em seu departamento".

"Fui aconselhada a não prestar o concurso de ingresso por vários colegas, porque ia competir com candidatos homens e formados na Escola".

"Pelo simples problema de pertencer ao sexo feminino. Mulher tem filhos, casa, marido e no entender de certos burocratas não se dedica ao trabalho como os machos".

"Problemas como desejar entrar numa disciplina composta somente por homens e ser barrada".

Com respeito as reivindicações como mulher dentro da Odontologia, as professoras responderam de um modo geral, colocando quase as mesmas coisas, que se transcrevem abaixo:

"Maior participação da mulher na composição dos membros nas diversas sociedades de classe".

"Maior aceitação e confiança por parte dos colegas".

"Embora a mulher tenha acesso aos órgãos de decisão nas faculdades não são dadas a devida atenc.ão às suas sugestões e participação".

"Ser mais valorizada".

"Que fosse encarada com mais seriedade".

"Creches ou maternais junto às Instituições para facilitar o trabalho das mães"'.

"Que as mulheres se sintam cada vez mais seguras de sua capacidade e competência, e que participem cada vez mais da vida universitária, liderando junto aos colegas do sexo masculino, todos os momentos que exijam uma tomada de posição forte e coerente".

\section{ANÅLISE DOS RESULTADOS}

Numa primeira aproximação, deve ressaltar-se que a mulher não tem compreendido a importância do seu papel no desenvolvimento da Odontologia e aparentemente sua situação é tranqüila, sem problemas quanto à relação técnica com seus colegas, porém alguns problemas começam a aparecer e podem, no futuro, representar contradições na profissão do Cirurgião Dentista.

Alguma informação obtida é de importância, apesar de não poder estruturar conclusões definitivas devido ao pouco volume de respostas recebidas $(10 \%)$ que indicam a falta de interesse das professoras no seu próprio conhecimento e no conhecimento da realidade.

Fica claro, desde uma perspectiva social, global, que o trabalho de organização da mulher não é independente da organização de toda a sociedade para uma eventual mudança porém é importante conhecer as formas em que se manifesta a dominação do modo de vida das pessoas e como, em algumas esferas específicas, o monopólio do conhecimento científico e tecnológico está, em maior quantidade, nas mãos do sexo masculino.

Nesta pesquisa notou-se a resposta muito aproximada da realidade, quanto à posição que as professoras ocupam dentro da categoria docente, sendo que apenas $3 \%$ chega a ser Titular ainda que existe um contingente considerável de docentes que entraram nos últimos 10 anos e que agora começam a ganhar posições na escala de autoridade.

Notou-se com interesse que somente a metade estão casadas e $54 \%$ não tem filhos, estando muito pouco delas na média Brasileira de 4 filhos, correspondendo no seu conjunto, à classe média econômica, cujos valores oscilam entre 1 e 2 filhos.

Isto porque a tareta docente separa a família quando do trabalho em instituições de ensino, que apresentam programas a serem cumpridos e funções es- 
pecíficas que não permitam uma liberação do tempo no lar.

Parece que o mesmo fenômeno dos Estados Unidos aqui é observado quanto às tarefas do lar e da profissão $(1,10)$.

Resulta interessante que as professoras em geral, não apontam problemas para seu ingresso à docência, ainda que acham 30\% como média de docentes nas suas faculdades. Isto significa a metade do que em realidade sucede, já que unicamente $18 \%$ (3) dos professores de Escolas e Faculdades no Brasil são do sexo feminino.

No estudo realizado não pode concluir-se com a existência de problemas da mulher no seu ingresso à docência superior.

Quem já está no processo aceita, até passivamente, poderia se dizer, a condição de minoria, numa profissão que está crescendo a expensas do sexo feminino em todo o Brasil.

Se requer estudos mais aprofundados sobre a situação e posição de classe das professoras e das profissionais na área da Odontologia no Brasil. Neste momento e com os dados obtidos neste trabalho, poderiam ser levantadas hipóteses que sugerem uma marginação por sexo nas Faculdades de Odontologia, as- sim, por exemplo:

$\mathrm{O}$ que faz com que o sexo feminino seja atraído e desenvolva mais sua atividade na área da Odontopediatria e Odontologia Social?

Qual o papel da mulher na direção de Faculdades, Departamentos ou Regências de Disciplinas?

Como desenvolver uma ação metodológica dirigida ao estudo da concepção do mundo que a mulher tem, quando é profissional da Odontologia?

Estas e outras pergundas devem ser objeto de questionamento constante a fim de aprofundar o conhecimento científico da mulher e seu papel dentro da profissão odontológica.

\section{SUMMARY}

"This article discusses the situation of female teachers in Dental Schools. of Brasil, analyzing the information gained in order to propose new studies in that way.

The result of the study is a young, single and assistants teacher's population, the majority works in pedodontics and social preventive dentistry and they did not have obstacles to work at the University".

\section{REFERÊNCIAS BIBLIOGRÁFICAS}

1. AUSTIN, G.B., MAHER, M.M.; LOMONACO, C.J. Women in dentistry and medicine: Attidudinal survey of educational experience. J. Dent. Educ., 37 (11): 11-7, Nov. 1973.

2. BUSTOS, Jaime. Tiempo integral util de ejercicio profissional odontologico, según sexo, en el decenio 1960-69 en Rio Grande do Sul, Brasil. Porto Alegre, Tese de Mestrado, 1973. 76p.

3. Conselho Federal de Odontologia. Relatório 1980. Brasília, Conselho Federal de Odontologia. Gráfica Editora Hamburg Ltda, 1981. 405p.

4. FIRESTONE, Shulamith. A dialética do sexo: um manifesto da revolução feminista. Rio de Janeiro, Labor do Brasil, 1976. 277p.

5. GIBBONS, K. et alii. La mujer en la Salud y el Desarollo. III. Algunas dificultades que plantea su actuación en la atención de salud. Bol. Of. Sanit. Panam.; Washington, 93(6): 522-31, Dec. 1982. 
6. Instituto Brasileiro de Geografia e Estatística. Censo de 1980. Rio de Janeiro. IBGE. 1982.

7. MATTELART, Michele. Mujeres e indústrias culturales. Naciones Unidas, UNESCO, 1981. 35p. (mimeo).

8. MCCREARY, C.P. \& GERSHEN, J.A. Changes in personality among male and female dental graduates. J. Dent. Educ. 46(5): 279-83, 1982.

9. MENDES, E.V. \& MENDES, Eunice. Odontologia. Alguns aspectos da odontologia brasileira. Petrópolis, Vozes, 1968. 172p.

10. MILLER, B.A.; Blair P.W.; Elmendorf M.L. La mujer en la Salud y el Desarollo. II. Algunos problemas de población, de influência y de higiene ambiental. Bol. Of. Sanit. Panam., Washington, 93(5): 442-51, Nov. 1982.

11. NAVARRO, Vicente. Women in heal th Care. New Engl. J. Med. 292:398-402, 1975.

12. Organização Mundial da Saúde. Atualidades: aumenta a proporção de mulheres em Farmácia, Odontologia e Medicina. A Saúde do Mundo, jun. 1981. p.30.

13. ROSEMBERG, Fulvia; Pinto, R.P.; Negrão, E.V. A educação da mulher no Brasil. São Paulo, Global, 1982. 112p.

14. STUDART, Heloneida. Mulher objeto de cama e mesa. 6.ed. Rio de Janeiro, Vozes, 1976. 53p.

15. SULLEROT, Evelyne. La mujer, tema candente. Madrid, Guadarrama, 1971. $251 p$.

16. VILLAR, José et alii. La mujer en la Salud y el Desarollo. I. Algunos problemas de salud de la mujer en el tercer mundo. Bol. Of. Sanit. Panam., Washington, 93(4): 327-38, Out. 1982. 